\title{
Effect of glutathione supplementation on swimmers' performance
}

Lubomir Petrov $^{1 \mathrm{ABCDE}}$, Albena Alexandrova ${ }^{1 \mathrm{ACD}}$, Mihail Kachaunov ${ }^{1 \mathrm{BD}}$, Radoslav Penov ${ }^{1 \mathrm{CD}}$, Tanya Sheytanova ${ }^{1 \mathrm{BD}}$, Stefan Kolimechkov ${ }^{2 \mathrm{CD}}$

${ }^{1}$ National Sports Academy, Sofia, Bulgaria

${ }^{2}$ STK SPORT, London, United Kingdom

Authors' Contribution: A - Study design; B - Data collection; C - Statistical analysis; D - Manuscript Preparation; E - Funds Collection

\begin{tabular}{|c|c|}
\hline \multicolumn{2}{|r|}{ (2) } \\
\hline $\begin{array}{l}\text { Background } \\
\text { and Study Aim }\end{array}$ & $\begin{array}{l}\text { Continuously increasing the volume and intensity of the training sessions often leads to overtraining. } \\
\text { It has been demonstrated that glutathione supplementation might improve the aerobic metabolism in } \\
\text { skeletal muscle and reduce exercise-induced muscle fatigue. The aim of the study was to assess the effect } \\
\text { of glutathione supplementation on fatigue, recovery processes, and competitive results of elite swimmers } \\
\text { during a six-week training period. }\end{array}$ \\
\hline $\begin{array}{l}\text { Material and } \\
\text { Methods }\end{array}$ & $\begin{array}{l}\text { Twenty-four elite swimmers ( } 10 \text { women and } 14 \text { men) from the Bulgarian national swimming team, with } \\
\text { a mean age of } 18.7 \pm 3.78 \text { years, took part in this double-blind placebo control study. The swimmers from } \\
\text { the experimental group were supplemented once a day with a capsule of } 250 \mathrm{mg} \text { glutathione, whilst the } \\
\text { swimmers from the control group took a placebo once a day. The urine concentration levels of cortisol } \\
\text { and cortisone, as well as the degree of overtraining, were evaluated on the } 1^{\text {st }}(\mathrm{T} 1), 14^{\text {th }}(\mathrm{T} 2), 28^{\text {th }}(\mathrm{T} 3) \text {, and } \\
42^{\text {nd }}(\mathrm{T} 4) \text { days. Anthropometric measurements and a nutritional assessment were performed at } \mathrm{T} 1 \text { and } \mathrm{T} 4 \text {. }\end{array}$ \\
\hline Results & $\begin{array}{l}\text { The swimmers showed a gradual decrease of cortisol and cortisone during the study, with significantly } \\
\text { lower concentrations in the experimental vs the control group at } \mathrm{T} 4(19.4 \mathrm{vs} 42.5 \mathrm{ng} / \mathrm{mL}, \mathrm{p}<0.05) \text {. At the } \\
\text { end of the study, the swimmers from the experimental group showed improvements in their time in } 41 \text { out } \\
\text { of the } 43 \text { swimming events, whilst those from the control group had significantly smaller improvements } \\
(-1.66 \text { vs }-0.97 \%, p<0.05) \text {. }\end{array}$ \\
\hline Conclusions: & $\begin{array}{l}\text { In conclusion, glutathione supplementation at a dose of } 250 \mathrm{mg} / \text { day for six weeks improves the adaptation } \\
\text { of elite swimmers towards training schedules, which is likely to lead to better sports results. } \\
\text { glutathione, supplements, elite, swimming, performance }\end{array}$ \\
\hline
\end{tabular}

\section{Introduction}

The main goal of elite athletes is to achieve high results in their sport, which is accomplished by doing great amounts of training as part of the preparatory process. However, continuously increasing the frequency, volume and intensity of the training sessions often leads to overtraining, from which days and even weeks are required in order to recover. About $30 \%$ of elite adolescent athletes reported experiencing a state of fatigue at least once in their careers, indicating an average of two episodes of overtraining lasting for a period of around four weeks. Overtraining was also observed in 5\% to $30 \%$ in swimmers during their sports season [1-4].

The appearance of overtraining in athletes is associated with the inducement of oxidative stress. Oxidative stress has a negative effect on cellular structures and their functions, and for athletes, these negative effects are mainly reflected in the change in muscle contraction functions and/or increased muscle damage and the rapid occurrence of fatigue [5-8]. Physical exercises increase oxidative stress throughout the body, and this outcome has been illustrated in a number of physical activities, including swimming [9-12].

Antioxidants can reduce the oxidative stress caused by high amounts and intensity of training workouts. A key non-enzymatic antioxidant is the reduced form of (c) Lubomir Petrov, Albena Alexandrova, Mihail Kachaunov, Radoslav Penov, Tanya Sheytanova, Stefan Kolimechkov, 2021 doi:10.15561/26649837.2021.0403 glutathione (GSH), which is the most widespread nonprotein thiol in the cells, and it has a concentration of 1-10 $\mathrm{mM}$ [13]. GSH has a high electron donation capacity, which determines its significant cell-reducing power [14], and it can directly neutralize active forms of oxygen $[15,16]$, in addition to being involved in the reduction of other antioxidants in the cell, including vitamins $\mathrm{E}$ and $\mathrm{C}$ [17]. GSH is a major co-factor of the antioxidant enzyme glutathione peroxidase (GPX) [18]. When oxidative stress is observed, GSH decreases [19], and its oxidized form GSSG increases, followed by a decrease in the GSH : GSSG ratio [20].

GSH takes part in the detoxification of foreign substances in the body by interacting and neutralizing them. It also supports the structure of proteins, takes part in intracellular transport and chelation of copper, modulates neurotransmitter receptor activity, activates T-lymphocytes and polymorphonuclear leukocytes, and others [21-24].

It has been shown through studies that changes in GSH and GSSG concentrations in the blood of athletes are observed during physical exercises. A number of these studies demonstrated that continuous submaximal training led to a decrease in GSH and an increase in GSSG [25-27]. It is assumed that decreased plasma GSH concentrations following physical exercise demonstrate increased GSH consumption in skeletal muscle, resulting in a reduced export rate from muscle into plasma [28]. 
Other authors reported only an increase in GSSG without significant change in GSH, thereby the GSH:GSSG ratio was reduced $[29,30]$.

The effect of increased levels of GSH on physical performance has been studied by applying $\mathrm{N}$-acetylcysteine (NAC) [31-34]. NAC is a reduced thiol donor with antioxidant properties which supports glutathione synthesis, since the acetylation of cysteine is the rate-limiting step in glutathione synthesis [35].

Only a few human clinical trials evaluated the effects of oral GSH supplementation. Witschi et al. administered a single oral dose of up to $3 \mathrm{~g}$ of GSH, given to seven healthy subjects, and no increase in blood GSH levels was found [36]. Allen et al. 2011 conducted a study, which involved 40 healthy subjects who consumed oral glutathione capsules (500 mg twice per day) or placebo capsules for a period of four weeks. The results showed that there were no changes in the levels of GSH, GSH:GSSG ratio, and some indicators of oxidative stress [37].

Data on animals in vivo demonstrate that oral GSH is absorbed in rats [38, 39]. Specifically, Hagen et al. showed a doubling of plasma GSH from 15 to $30 \mu \mathrm{mol} / \mathrm{L}$ within 120 minutes after oral administration in rats, and suggested that dietary GSH is principally absorbed in the jejunum [39]. Kovacs-Nolan et al. demonstrated, in in vitro and ex vivo intestinal absorption models, that intact glutathione can be transported between human intestinal epithelial cells [40]. In addition, Park et al. reported that the plasma glutathione concentration is transiently elevated after oral glutathione supplementation, which suggests that exogenous glutathione can be absorbed into the body and act as an important glutathione supply [41].

In 2015, Aoi et al. demonstrated that glutathione supplementation improves the aerobic metabolism in skeletal muscle, leading to reduced exercise-induced muscle fatigue by elevating Peroxisome proliferatoractivated receptor- $\gamma$ coactivator- $1 \alpha$ (PGC-1 $\alpha$ ) [42]. PGC$1 \alpha$ has been shown to be a key transcriptional co-activator, providing a mechanistic insight into nuclear regulatory pathways in the biogenesis of mitochondria in skeletal muscle [43].

The aim of the study was to assess the effect of glutathione supplementation intake on fatigue rate, recovery processes, and competitive results of elite swimmers during a six-week training period.

\section{Material and Methods}

\section{Participants}

Twenty-four elite swimmers (10 women and 14 men) from the Bulgarian national swimming team, with an average age of $18.7 \pm 3.78$ years (from 15 to 25 years), took part in this double-blind placebo control study. The research was performed in accordance with the Declaration of Helsinki for Human Researches [45]. The swimmers were familiarized with the details regarding the purposes of the study, and an informed consent was obtained from each participant.

Design of the study

The swimmers were divided into two comparable groups according to their competition results, gender, and age. Each group consisted of five women and seven men. The swimmers from the first group (experimental) were supplemented once a day with a capsule of $250 \mathrm{mg}$ glutathione, whilst the swimmers from the second group (control) took placebo once a day (one capsule with 250 mg glucose).

The swimmers were tested for a six-week period, starting two weeks after the National Team Championship and finishing two weeks before the National Individual Championship (both in a $50 \mathrm{~m}$ long pool). The assessments were conducted each Monday in the mornings (after 60 hours of rest) every two weeks: on the $1^{\text {st }}(\mathrm{T} 1), 14^{\text {th }}(\mathrm{T} 2)$, $28^{\text {th }}$ (T3), and $42^{\text {nd }}$ days (T4). The swimmers' degree of overtraining was evaluated four times at T1, T2, T3 and T4 by the Training Distress Scale (TDS) and by assessing the urine concentration of cortisol and cortisone. Additionally, anthropometric measurements and a nutritional assessment were performed at $\mathrm{T} 1$ and $\mathrm{T} 4$.

\section{Training programme}

The swimmers were following a three-season planning in their annual programme. This study took place in the summer season (3rd macrocycle) from April to July, in which the swimmers were performing their training sessions in a $50 \mathrm{~m}$ long pool. The reported sixweek period in this study is part of the general preparation phase, and it started right after the two-week recovery phase after the main competition. The swimmers trained twice a day from Monday to Friday performing a total of ten training sessions per week. During this period, the training process was associated with gradually increasing the training volume, starting from $40 \mathrm{~km}$ for the first week and finishing at $65 \mathrm{~km}$ for the last one. The main goals for this phase were to improve aerobic capacity and maintain anaerobic power and speed. The training has to produce central circulatory and respiratory adaptations which will improve the delivery of oxygen and nutrients to the muscles [45]. As a result of that, an increase of $\mathrm{VO}_{2} \mathrm{max}$ is expected. The training programme applied in this research, including training volume $(\mathrm{km})$ and training zones ( $\%$ of all volume), is shown in Table 1 .

Anthropometry

The anthropometric measurements of the swimmers were taken at the National Centre for Sports Medicine in Bulgaria. Height was taken with an accuracy of $0.1 \mathrm{~cm}$, and body weight was recorded with an accuracy of 0.1 $\mathrm{kg}$. Skinfolds were measured to the nearest $0.1 \mathrm{~cm}$ by using the Lange Skinfold Calliper, Beta Technology Inc, Cambridge, USA. Arm, thigh and calf circumferences was measured to the nearest $0.1 \mathrm{~cm}$ with the Lufkin W606PM tape measure. The percentage of body fat (Fat $\%$ ) was determined by the sum of seven skinfolds, using Jackson and Pollock's equations [46]. The percentage of total body skeletal muscle mass (MM\%) was calculated by using the Lee et al's equations [47].

Nutritional assessment

The food frequency questionnaire (FFQ) [48, 49], which was applied in this study to assess the nutrition of the swimmers, included questions about the weekly use 
Table 1. Six-week training programme of the elite swimmers from this study

\begin{tabular}{|c|c|c|c|c|c|c|}
\hline Week & 1 & 2 & 3 & 4 & 5 & 6 \\
\hline Training zones/Volume (km) & 40 & 45 & 50 & 55 & 60 & 65 \\
\hline I. Basic Endurance HR 120-150 & $59 \%$ & $59 \%$ & $59 \%$ & $50 \%$ & $50 \%$ & $50 \%$ \\
\hline II. Threshold Endurance HR 150-180 & $25 \%$ & $25 \%$ & $25 \%$ & $25 \%$ & $25 \%$ & $25 \%$ \\
\hline III. High performance endurance HR >180 & $4 \%$ & $4 \%$ & $4 \%$ & $8 \%$ & $8 \%$ & $8 \%$ \\
\hline $\begin{array}{l}\text { IV. Anaerobic: Lactate tolerance }+ \text { Lactate production + } \\
\text { Race pace training }\end{array}$ & $2 \%$ & $2 \%$ & $2 \%$ & $4 \%$ & $4 \%$ & $4 \%$ \\
\hline V. Sprint & $3 \%$ & $3 \%$ & $3 \%$ & $3 \%$ & $3 \%$ & $3 \%$ \\
\hline VI. Recovery HR < 120 & $7 \%$ & $7 \%$ & $7 \%$ & $10 \%$ & $10 \%$ & $10 \%$ \\
\hline
\end{tabular}

$\mathrm{HR}$ - heart rate in beats per minute (bpm)

of basic food products and questions about the age, sports experience, and number of training sessions per week. The composition and energy value of different groups of food were calculated based on the USDA National Nutrient Database - Release 28 [50]. The FFQ and the data tables needed for calculations are available on the internet [51].

Based on the results, the daily intake of proteins, carbohydrates and fats, relative daily protein intake per kilogram body mass (RDPI), relative carbohydrate intake (RDCI), relative fat intake (RDFI), and the energy contribution of each nutrient $(\mathrm{E} \%)$, in addition to the total daily energy intake $(\mathrm{kcal} / 24 \mathrm{~h})$ and relative energy intake (RDEN), were calculated. The basal metabolic rate (BMR $\mathrm{kcal} / 24 \mathrm{~h}$ ) was calculated by using the equations of Harris and Benedict [52]. The estimated daily and relative energy needs (DEN and RDEN) were calculated by multiplying BMR by the coefficient of physical activity $(\mathrm{k})$ according to the number of weekly training sessions (BMR kcal/24h $\mathrm{x}(1.2+0.08 \mathrm{x}$ number of sessions $)$ [52].

Recovery and overtraining assessment

The rate of recovery and the level of overtraining were assessed by using the Training Distress Scale (TDS), which was proposed and validated by Grove et al. [44]. It consists of nineteen questions, which evaluate the symptoms of distress in athletes. These symptoms include various statements related to changes in emotional state, general fatigue, concentration difficulties, physical discomfort, sleep and appetite disturbances. The swimmers responded to the questions, indicating the degree to which each symptom corresponds to their individual state during the last 48 hours. The grade was determined by a fivepoint bipolar scale, ranging from "none" (0 points) to "excessive" (4 points). The final result (TDS score) was the sum of the points from all nineteen questions.

Cortisol and Cortisone urine concentration assessment

The concentration of cortisol and cortisone was determined by the relative density of the urine specimens, from which the measured hormonal concentrations were adjusted. Samples were pre-treated, then analysed sequentially by a high-performance liquid chromatograph (HPLC) and a mass spectrometer.

\section{Swimming results}

The results achieved by the swimmers at the National Team Championships (two weeks before the start of the experiment) were compared to the results from the National Championships, which was held two weeks after the end of the experiment. From the results for each swimming event recorded in the first competition, we subtracted the results from the second competition, and the difference was presented as a percentage of the first time (negative values show an improvement in the achievements form the second competition).

Statistical analyses

The statistical analyses were performed by the SPSS Statistics 19 software (IBM, USA), using descriptive statistics and one-way ANOVA for dependent samples with the Bonferroni post hoc test. The data from the Training Distress Scale (TDS) did not show a normal distribution when using the Kolmogorov-Smirnov test of normality, and, therefore, non-parametric ANOVA for repeated measurements (Friedman test) was applied. The average improvement in performance was analysed by using Independent-samples t-test, and the improved swimming results and worsened swimming results were analysed by Chi-square test for frequency distributions. The results are expressed as mean values $\pm \mathrm{SD}$ in the text and tables, and as mean $\pm \mathrm{SE}$ in the figures.

\section{Results}

Anthropometry

The mean age of the swimmers from the experimental group was $17.6 \pm 3.67$ years, and in those from the control group was $18.4 \pm 4.67$ years. The anthropometric parameters of the swimmers in this study are presented in Figure 1 . There were no statistically significant differences in the parameters, neither between the experimental and control groups, nor between the initial baseline (T1) and final measurements (T4).

\section{Nutrition}

No significant differences were found between the genders in all of the groups in this study in terms of their nutrition, and, therefore, the analyses were performed for both men and women together. The relative daily energy needs (RDEN) and relative daily energy intake (RDEI) of the swimmers in this study are presented in Figure 2. The data shows no significant differences between the estimated energy needs and the calculated energy intake, which was confirmed by the stable anthropometric 

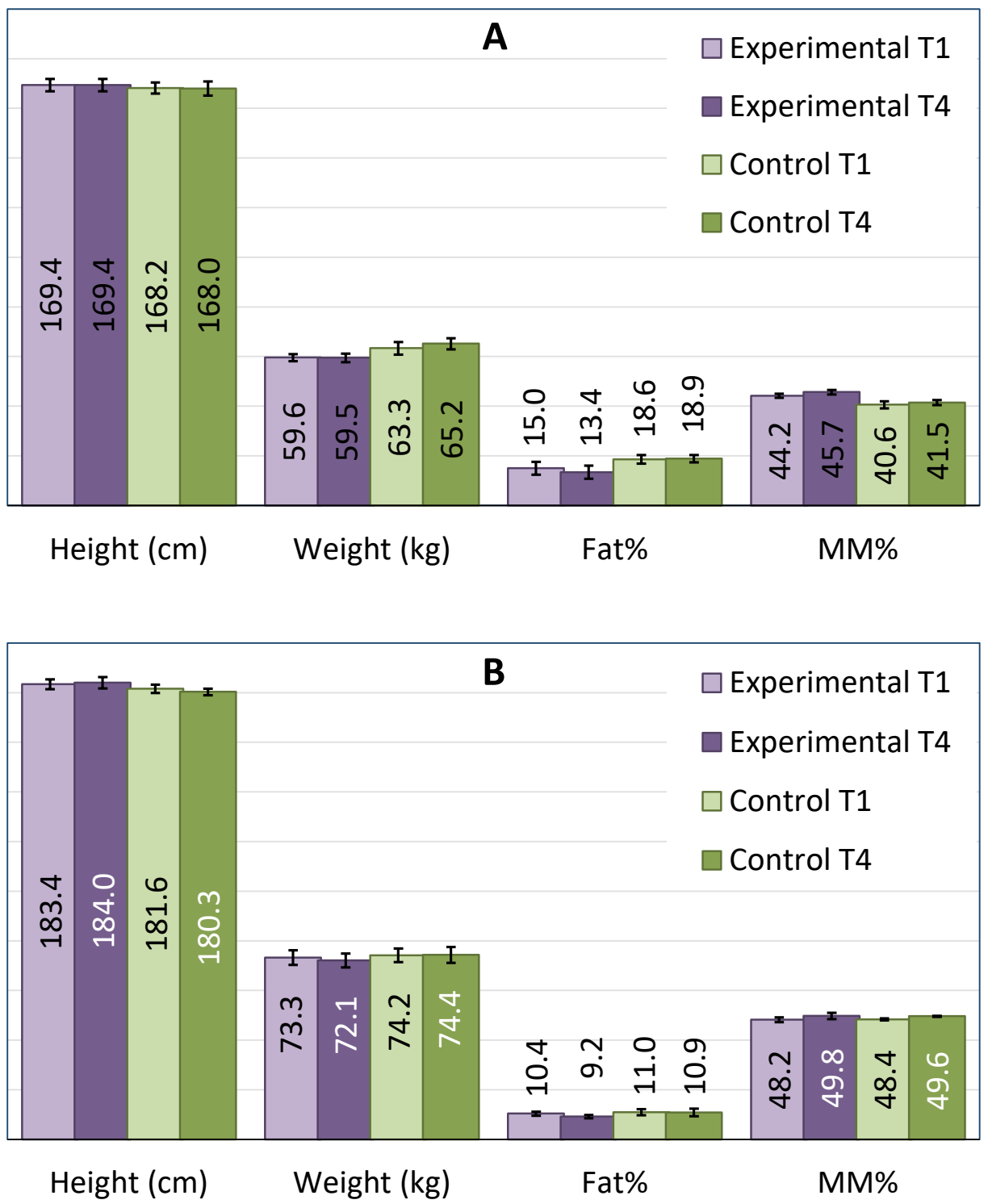

Figure 1. Anthropometric parameters of the female swimmers (A) and male swimmers (B) from the experimental and control groups on the $1^{\text {st }}(\mathrm{T} 1)$ and the $42^{\text {nd }}(\mathrm{T} 4)$ days of the six-week training period.

parameters over time (Figure 1). There were no significant differences between the experimental and the control group, nor between baseline (T1) and final nutritional assessment (T4).

The relative daily protein intake (RDPI), relative daily fat intake (RDFI), and relative daily carbohydrate intake (RDCI) of the swimmers are presented in Figure 3 . There was a correlation between the amounts of the main macronutrients consumed by the swimmers in this study and the recommended norms for swimmers with similar training [54] in all four assessments. There were no significant differences in the relative amounts of the macronutrients between the experimental and the control groups, nor between the baseline (T1) and final nutritional assessment (T4).

Training Distress Scale (TDS)

The results of the TDS assessment showed a reduction in the frequency of the overtraining symptoms at the end of the six-week training period (Figure 4), which was contrary to our expectations. There was no significant difference in the TDS scores between the experimental and control groups at the final assessment (T4).

\section{Hormones}

The concentration of cortisol hormone in the morning urine of the subjects tested showed a gradual decrease during the six-week training period (Figure 5). A statistically significantly lower cortisol concentration was found in the morning urine of the swimmers from the experimental group at the final measurement (T4). The same dynamics were observed in the concentration of cortisone and the sum of the cortisol and cortisone concentrations (data not shown).

\section{Competition results}

The results of the swimmers at the National Team Championship, which took place two weeks before the start of the experiment, and the results at the National 


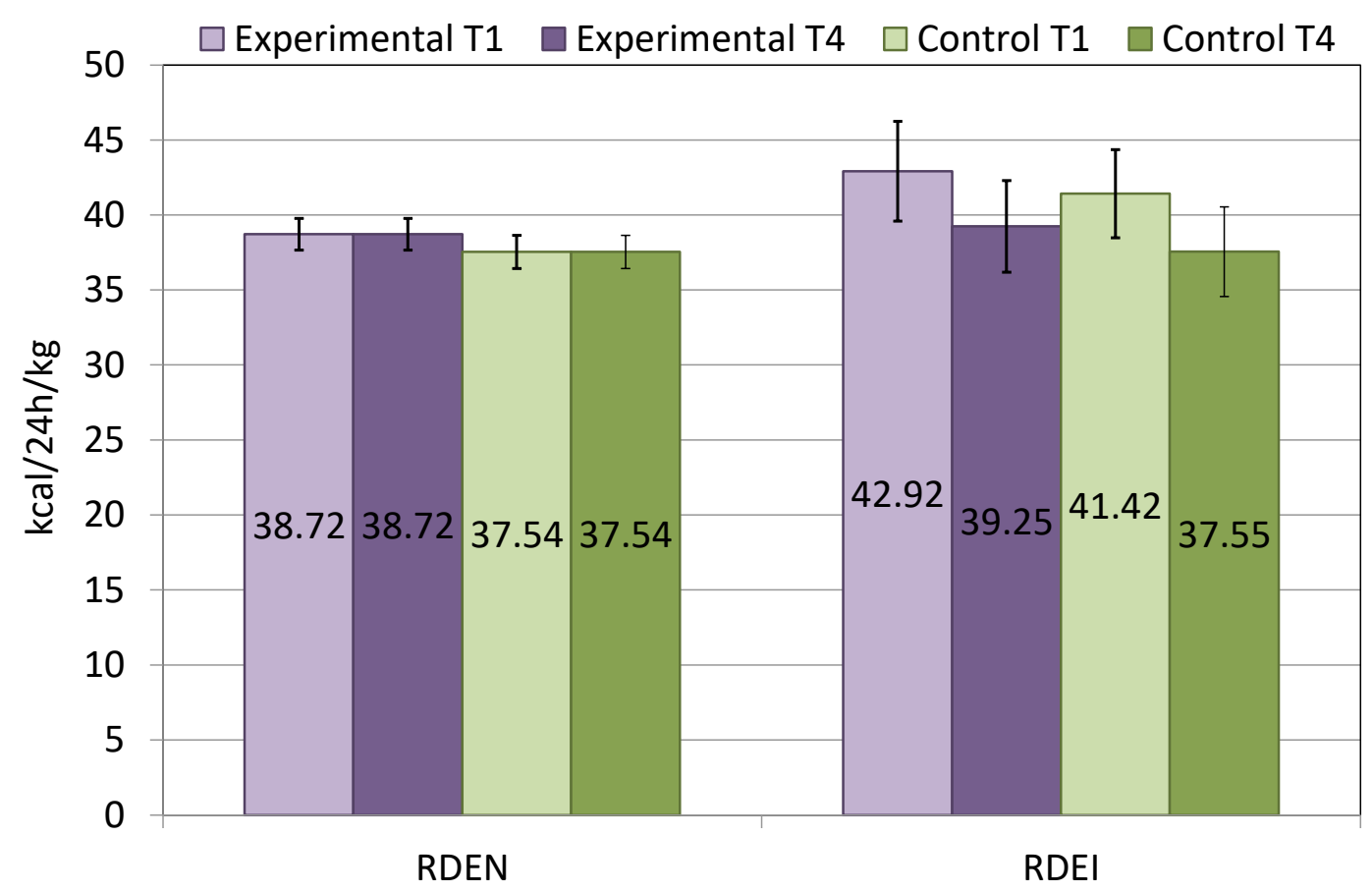

Figure 2. Relative daily energy needs (RDEN) and relative daily energy intake (RDEI) of the swimmers from the experimental $(n=12)$ and the control $(n=12)$ groups on the $1^{\text {st }}(T 1)$ and the $42^{\text {nd }}(T 4)$ days of the six-week training period.

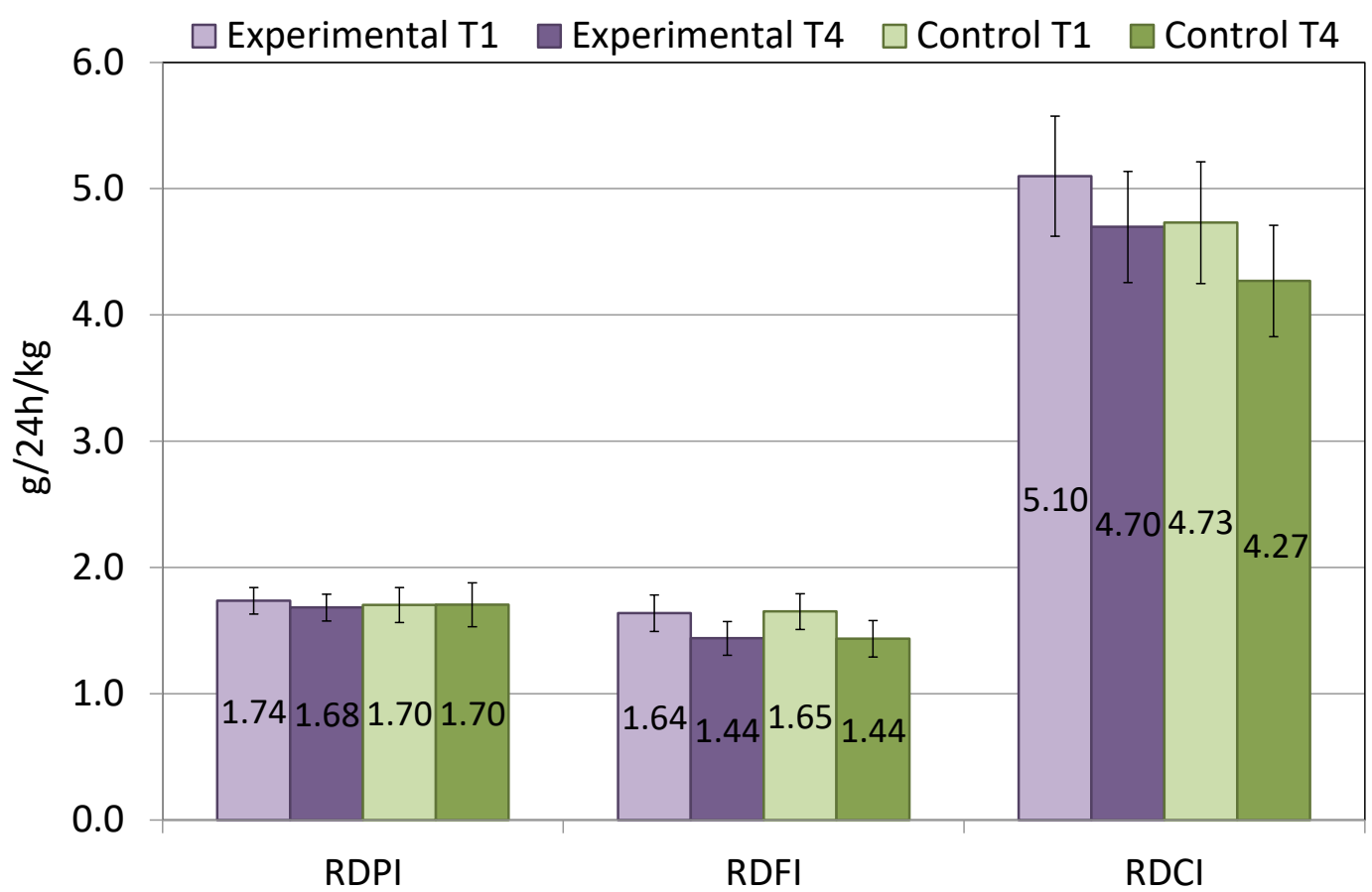

Figure 3. Relative daily protein intake (RDPI), relative daily fat intake (RDFI) and relative daily carbohydrate intake $(R D C l)$ of the swimmers from the experimental $(n=12)$ and the control $(n=12)$ groups on the $1^{\text {st }}(T 1)$ and the $42^{\text {nd }}(T 4)$ days of the six-week training period. 


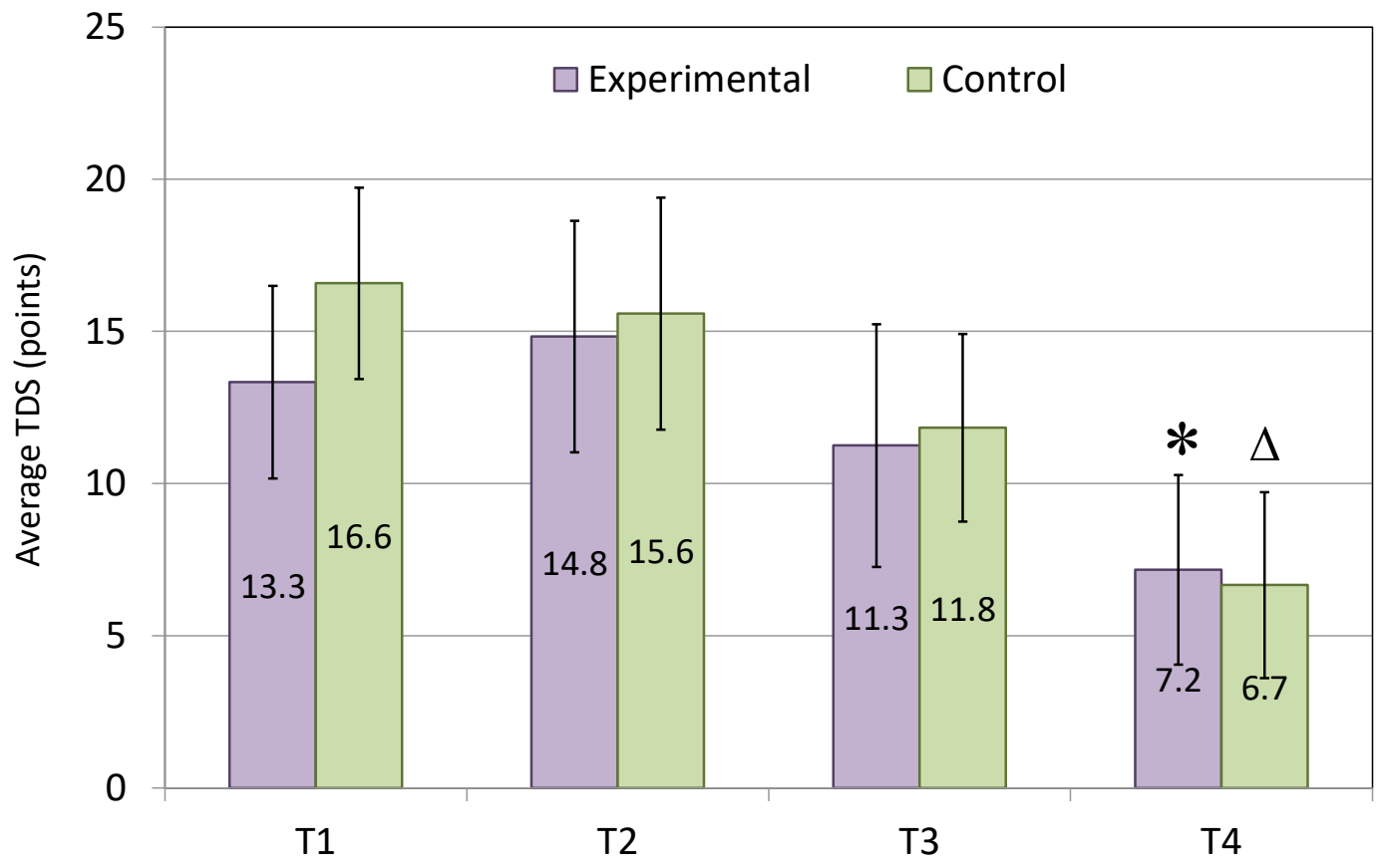

Figure 4. Training distress scores (TDS) of the swimmers from the experimental $(n=12)$ and the control ( $n=12)$ groups on the $1^{\text {st }}(\mathrm{T} 1), 14^{\text {th }}(\mathrm{T} 2), 28^{\text {th }}(\mathrm{T} 3)$ and $42^{\text {nd }}(\mathrm{T} 4)$ days of the six-week training period. ${ }^{*}-\mathrm{p}<0.05$ vs Experimental T2; $\Delta-\mathrm{p}<0.05$ vs Control T1 and Control T2

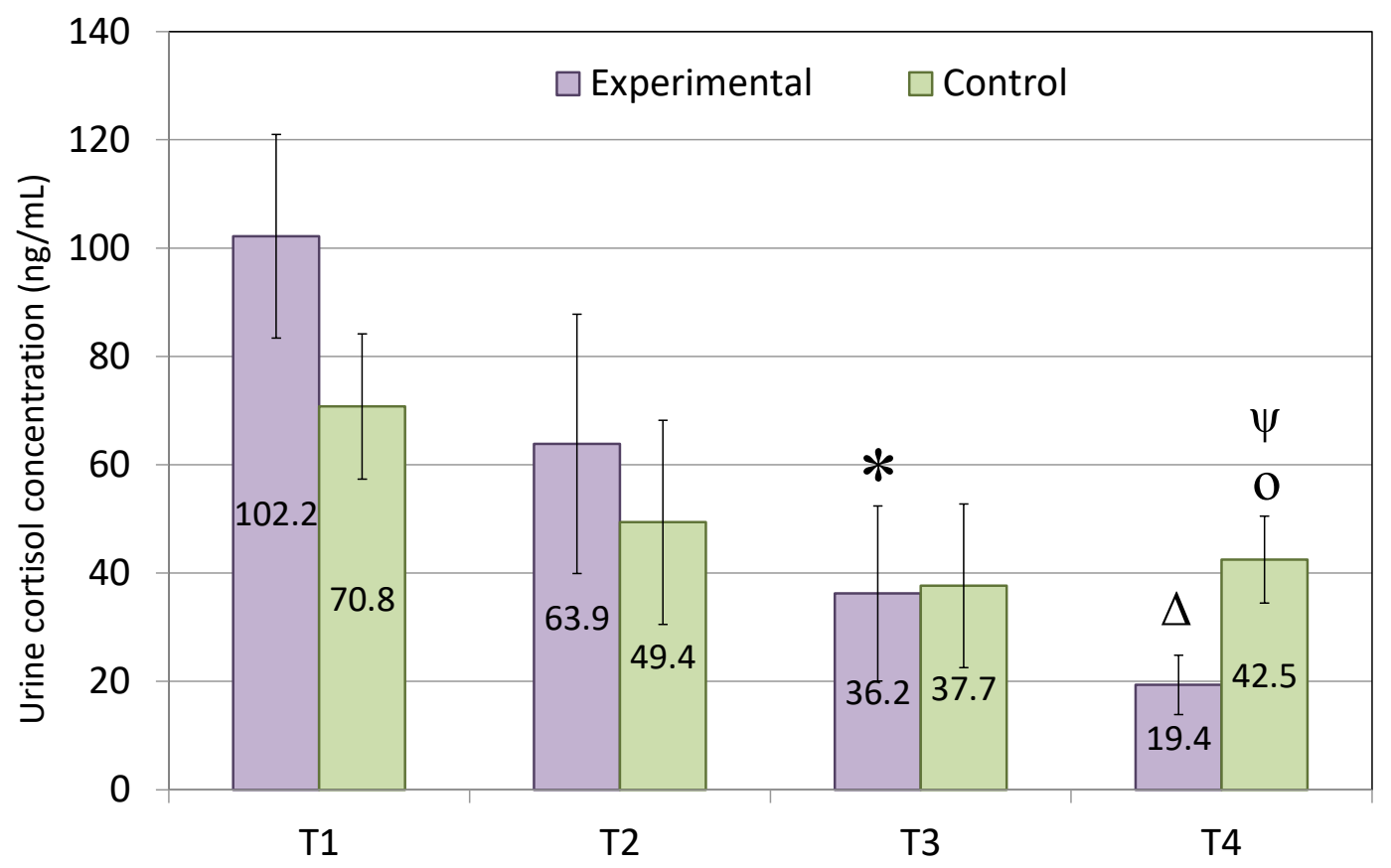

Figure 5. Dynamics of urine cortisol concentration of the swimmers from the experimental ( $n=12)$ and the control $(n=12)$ groups on the $1^{\text {st }}(T 1), 14^{\text {th }}(T 2), 28^{\text {th }}(T 3)$ and $42^{\text {nd }}(T 4)$ days of the sixweek training period. ${ }^{*}-\mathrm{p}<0.05$ vs Experimental T1; $\Delta-\mathrm{p}<0.05$ vs Experimental T1 and T2; $\mathrm{O}-\mathrm{p}<0.05$ vs Control T1; $\psi-\mathrm{p}<0.05$ vs Experimental T4 
Table 2. Changes of competition results of the swimmers in this study.

\begin{tabular}{llll}
\hline Parameter & $\begin{array}{l}\text { Experimental } \\
\text { Group }\end{array}$ & $\begin{array}{l}\text { Control } \\
\text { Group }\end{array}$ & $\mathbf{p}$ \\
\hline Number of swimmers & 12 & 12 & $0.0329 \mathrm{a}$ \\
Number of swimming competition events & 43 & 42 & $0.0004 \mathrm{~b}$ \\
Average swimming results improvements (\%) & $-1.66 \pm 1.20$ & $-0.97 \pm 1.68$ & $0.014 \mathrm{~b}$ \\
Number of worsened swimming results & 2 & 13 & 4 \\
\hline
\end{tabular}

a - t-test for independent samples; $\mathrm{b}$ - Chi-square test

Championship, which took place two weeks after the end of the study, were compared (Table 2). The swimmers from the experimental group took part in each event from both competitions (a total of 43 events), and showed an improvement in their time in 41 of them, with an average of $-1.66 \pm 1.20 \%$. Moreover, none of them showed worse average results. On the contrary, the swimmers from the control group, who took part in both competitions in a total of 42 events, showed an improvement in only 29 events, with an average of $-0.97 \pm 1.68 \%$, and four of the participants showed worse average results. The average improvement in performance (analysed with independentsamples t-test) and the distribution of both improved swimming results and worsened swimming results (analysed with Chi-square test), were all statistically significant in favour of the experimental group (Table 2).

\section{Discussion}

The stable anthropometric parameters, as well as the balanced nutrition consistent with the recommendations for elite swimmers, in addition to the decreased TDS scores and decreased values of cortisol and cortisone during this study, showed a very good adaptation amongst the swimmers towards the increasing training workload, with a good average recovery rate within each training week.

The greater progress in results from competitions, and the lower levels of stress hormones at the end of the study in the experimental group, suggest a positive role of the glutathione (GSH) as a supplement.

Our double-blind placebo control study supports the possibility of using glutathione supplementation in order to directly or indirectly increase the GSH levels in the body. These conclusions are in agreement with some authors who have researched the effects of GSH on experimental animals [38-40, 42], as well as other researchers who have observed an increase in plasma GSH levels in humans after an oral supplementation with a much higher dose of GSH (50 mg/kg body weight) [41] than the one in our study.

The limitation in our study was our inability to determine the plasma glutathione levels, as the ethical committee did not give permission for that. The reason for this was that some of the swimmers from our study were under the age of 18 , and the number of the other participants was not sufficient to obtain reliable results.

To confirm the positive effect of glutathione supplementation and to reveal the mechanism of its action, additional biochemical studies on changes in GSH level and oxidative status in athletes with a high degree of exercise load are required.

\section{Conclusions}

The supplementation of glutathione at a dose of 250 $\mathrm{mg}$ per day for six weeks improves the adaptation of elite level swimmers towards training schedules, which is likely to lead to higher achievements as far as sports results are concerned.

\section{Conflict of interests}

The authors declare that there is no conflict of interests. 


\section{References}

1. O'Connor PJ, Morgan WP, Raglin JS, Barksdale CM, Kalin NH. Mood state and salivary cortisol levels following overtraining in female swimmers. Psychoneuroendocrinology. 1989;14(4):303-10. https://doi.org/10.1016/0306-4530(89)90032-2

2. Morgan WP, Brown DR, Raglin JS, O'Connor PJ, Ellickson KA. Psychological monitoring of overtraining and staleness. Br J Sports Med. 1987;21(3):107-14. https://doi.org/10.1136/bjsm.21.3.107

3. Hooper SL, MacKinnon LT, Hanrahan S. Mood states as an indication of staleness and recovery. International Journal of Sport Psychology. 1997;28(1):1-12.

4. Mateu P, Ingles E, Torregrossa M, Marques RFR, Stambulova N, Vilanova A. Living Life Through Sport: The Transition of Elite Spanish StudentAthletes to a University Degree in Physical Activity and Sports Sciences. Frontiers in Psychology. 2020;11. https://doi.org/10.3389/fpsyg.2020.01367

5. Goldhaber JI, Qayyum MS. Oxygen free radicals and excitation-contraction coupling. Antioxidants \& redox signaling. 2000;2(1):55-64. https://doi.org/10.1089/ars.2000.2.1-55

6. Reid MB. Nitric oxide, reactive oxygen species, and skeletal muscle contraction. Med Sci Sports Exerc. 2001;33(3):371-6. https://doi.org/10.1097/00005768-200103000-00006

7. Joro R, Korkmaz A, Lakka TA, Uusitalo ALT, Atalay M. Plasma irisin and its associations with oxidative stress in athletes suffering from overtraining syndrome. Physiology International. 2020;107(4):513-526. https://doi.org/10.1556/2060.2020.00037

8. Luti S, Modesti A, Modesti PA. Inflammation, Peripheral Signals and Redox Homeostasis in Athletes Who Practice Different Sports. Antioxidants. 2020;9(11). https://doi.org/10.3390/antiox9111065

9. Gougoura S, Nikolaidis MG, Kostaropoulos IA, Jamurtas AZ, Koukoulis G, Kouretas D. Increased oxidative stress indices in the blood of child swimmers. European Journal of Applied Physiology. 2007;100(2):235-9. https://doi.org/10.1007/s00421-007-0423-x

10.Koivisto AE, Olsen T, Paur I, Paulsen G, Bastani NE, Garthe I, et al. Effects of antioxidant-rich foods on altitude-induced oxidative stress and inflammation in elite endurance athletes: A randomized controlled trial. Plos One. 2019;14(6). https://doi.org/10.1371/journal.pone.0217895

11. Michalickova D, Minic R, Kotur-Stevuljevic J, Andjelkovic M, Dikic N, Kostic-Vucicevic M, et al. Changes in Parameters of Oxidative Stress, Immunity, and Behavior in Endurance Athletes During a Preparation Period in Winter. Journal of Strengthand ConditioningResearch.2020;34(10):2965-2973. https://doi.org/10.1519/jsc.0000000000002780

12.Souissi W, Bouzid MA, Farjallah MA, Ben Mahmoud L, Boudaya M, Engel FA, et al. Effect of Different Running Exercise Modalities on Post-Exercise Oxidative Stress Markers in Trained Athletes. International Journal of Environmental Research and Public Health. 2020;17(10). https://doi.org/10.3390/ijerph17103729

13.Zhang H, Forman HJ. Glutathione synthesis and its role in redox signaling. Seminars in cell \& developmental biology. 2012;23(7):722--8. https://doi.org/10.1016/j.semcdb.2012.03.017

14.Kidd PM. Glutathione: Systemic protectant against oxidative and free radical damage. Alternative Medicine Review. 1997:2:155-76.

15.Griffith OW. Biologic and pharmacologic regulation of mammalian glutathione synthesis. Free Radical
Biology \& Medicine. 1999;27(9-10):922-35. https://doi.org/10.1016/S0891-5849(99)00176-8

16.Powers SK, Jackson MJ. Exercise-induced oxidative stress: cellular mechanisms and impact on muscle force production. Physiological reviews. 2008;88(4):1243-76. https://doi.org/10.1152/physrev.00031.2007

17.Ji L, La J. Antioxidant defense:effects of aging and exercise. In: Radak Z, editor. Free Radicals in Exercise and Aging. Champaign, IL: Human Kinetics; 2000. P. 35-72.

18. Brigelius-Flohe R, Maiorino M. Glutathione peroxidases. Biochimica et Biophysica Acta. 2013;1830(5):3289-303. https://doi.org/10.1016/j.bbagen.2012.11.020

19.Jones DP, Carlson JL, Mody VC, Cai J, Lynn MJ, Sternberg P. Redox state of glutathione in human plasma. Free Radical Biology \& Medicine. 2000;28(4):625-35. https://doi.org/10.1016/S0891-5849(99)00275-0

20.Owen JB, Butterfield DA. Measurement of Oxidized/ Reduced Glutathione Ratio In: Bross P, Gregersen $\mathrm{N}$, editors. Protein Misfolding and Cellular Stress in Disease and Aging. Totowa, NJ: Humana Press; 2010. https://doi.org/10.1007/978-1-60761-756-3_18

21.Kaplowitz N, Aw TY, Ookhtens M. The regulation of hepatic glutathione. Annual Review of Pharmacology and Toxicology. 1985;25:715-44. https://doi.org/10.1146/annurev.pa.25.040185.003435

22.Wu G, Fang YZ, Yang S, Lupton JR, Turner ND. Glutathione metabolism and its implications for health. The Journal of Nutrition. 2004;134(3):489-92. https://doi.org/10.1093/jn/134.3.489

23.de Oliveira DCX, Rosa FT, Simoes-Ambrosio L, Jordao AA, Deminice R. Antioxidant vitamin supplementation prevents oxidative stress but does not enhance performance in young football athletes. Nutrition. 2019;63-64:29-35. https://doi.org/10.1016/j.nut.2019.01.007

24.Zanella PB, August PM, Alves FD, Matte C, de Souz CG. Association of Healthy Eating Index and oxidative stress in adolescent volleyball athletes and non-athletes. Nutrition. 2019;60:230-234. https://doi.org/10.1016/j.nut.2018.10.017

25.Gohil K, Viguie C, Stanley WC, Brooks GA, Packer L. Blood glutathione oxidation during human exercise. Journal of Applied Physiology, 1988;64:115-9. https://doi.org/10.1152/jappl.1988.64.1.115

26.Laires MJ, Madeira F, Sergio J, Colaco C, Vaz C, Felisberto GM, et al. Preliminary study of the relationship between plasma and erythrocyte magnesium variations and some circulating pro-oxidant and antioxidant indices in a standardized physical effort. Magnesium Research. 1993;6(3):233-8.

27.Viguie CA, Frei B, Shigenaga MK, Ames BN, Packer L, Brooks GA. Antioxidant status and indexes of oxidative stress during consecutive days of exercise. Journal of Applied Physiology, 1993;75:566-72. https://doi.org/10.1152/jappl.1993.75.2.566

28.Kretzschmar M, Muller D. Aging, training and exercise. A review of effects on plasma glutathione and lipid peroxides. Sports Med. 1993;15(3):196-209. https://doi.org/10.2165/00007256-199315030-00005

29. Tessier F, Margaritis I, Richard MJ, Moynot C, Marconnet P. Selenium and training effects on the glutathione system and aerobic performance. MedSciSports Exerc. 1995;27(3):390-6. https://doi.org/10.1249/00005768-199503000-00015

30.Sastre J,Asensi M, Gasco E, Pallardo FV, Ferrero JA, Furukawa $\mathrm{T}$, et al. Exhaustive physical exercise causes oxidation of glutathione status in blood: prevention by antioxidant administration. American Journal of Physiology-Regulatory, 
Integrative and Comparative Physiology, 1992;263:R992-5. https://doi.org/10.1152/ajpregu.1992.263.5.R992

31.Paschalis V, Theodorou AA, Margaritelis NV, Kyparos A, Nikolaidis MG. N-acetylcysteine supplementation increases exercise performance and reduces oxidative stress only in individuals with low levels of glutathione. Free Radical Biology \& Medicine. 2018;115:288-97. https://doi.org/10.1016/j.freeradbiomed.2017.12.007

32.Kerksick CM, Kreider RB, Willoughby DS. Intramuscular adaptations to eccentric exercise and antioxidant supplementation. Amino Acids. 2010;39(1):219-32. https://doi.org/10.1007/s00726-009-0432-7

33. Slattery KM, Dascombe B, Wallace LK, Bentley DJ, Coutts AJ. Effect of N-acetylcysteine on cycling performance after intensified training.MedSciSportsExerc. 2014;46(6):1114-23. https://doi.org/10.1249/MSS.0000000000000222

34.Antonioni A, Fantini C, Dimauro I, Caporossi D. Redox homeostasis in sport: do athletes really need antioxidant support? Res Sports Med. 2019;27(2):147-165. https://doi.org/10.1080/15438627.2018.1563899

35. Whillier S, Raftos JE, Chapman B, Kuchel PW. Role of $\mathrm{N}$-acetylcysteine and cystine in glutathione synthesis in human erythrocytes. Redox Report: Communications in Free Radical Research. 2009;14(3):115-24. https://doi.org/10.1179/135100009X392539

36. Witschi A, Reddy S, Stofer B, Lauterburg BH. The systemic availability of oral glutathione. European Journal of Clinical Pharmacology. 1992;43(6):667-9. https://doi.org/10.1007/BF02284971

37.Allen J, Bradley RD. Effects of oral glutathione supplementation on systemic oxidative stress biomarkers in human volunteers. Journal of Alternative and Complementary Medicine. 2011;17(9):827-33. https://doi.org/10.1089/acm.2010.0716

38.Favilli F, Marraccini P, Iantomasi T, Vincenzini MT. Effect of orally administered glutathione on glutathione levels in some organs of rats: role of specific transporters. The British Journal of Nutrition. 1997;78(2):293-300. https://doi.org/10.1079/BJN19970147

39. Hagen TM, Wierzbicka GT, Bowman BB, Aw TY, Jones DP. Fate of dietary glutathione: disposition in the gastrointestinal tract. American Journal of PhysiologyGastrointestinal and Liver Physiology, 1990;259:G530-5. https://doi.org/10.1152/ajpgi.1990.259.4.G530

40.Kovacs-Nolan J, Rupa P, Matsui T, Tanaka M, Konishi $\mathrm{T}$, Sauchi $\mathrm{Y}$, et al. In vitro and ex vivo uptake of glutathione (GSH) across the intestinal epithelium and fate of oral GSH after in vivo supplementation. Journal of Agricultural and Food Chemistry. 2014;62(39):9499-506. https://doi.org/10.1021/jf503257w

41.Park EY, Shimura N, Konishi T, Sauchi Y, Wada S, Aoi W, et al. Increase in the protein-bound form of glutathione in human blood after the oral administration of glutathione. Journal of Agricultural and Food Chemistry. 2014;62(26):6183-9. https://doi.org/10.1021/jf501338z
42.Aoi W, Ogaya Y, Takami M, Konishi T, Sauchi Y, Park $\mathrm{E}$, et al. Glutathione supplementation suppresses muscle fatigue induced by prolonged exercise via improved aerobic metabolism. J Int Soc Sports Nutr, 2015;12:7. https://doi.org/10.1186/s12970-015-0067-x

43.Correia JC, Ferreira DMS, Ruas JL. Intercellular: local and systemic actions of skeletal muscle PGC-1s. Trends in Endocrinology \& Metabolism, 2015;26:305-14. https://doi.org/10.1016/j.tem.2015.03.010

44.World Medical Association Declaration of Helsinki: Ethical Principles for Medical Research Involving Human Subjects. JAMA, 2013;310:2191. https://doi.org/10.1001/jama.2013.281053

45.Maglischo E. Swimming fastest. Human Kinetics; 2003.

46.Jackson AS, Pollock ML. Generalized equations for predicting body density of men. The British Journal of Nutrition. 1978;40(3):497-504. https://doi.org/10.1079/BJN19780152

47.Lee RC, Wang Z, Heo M, Ross R, Janssen I, Heymsfield SB. Total-body skeletal muscle mass: development and cross-validation of anthropometric prediction models. Am J Clin Nutr. 2000;72(3):796-803. https://doi.org/10.1093/ajen/72.3.796

48. Miteva S, Yanev I, Kolimechkov S, Petrov L, Mladenov L, Georgieva V, et al. Nutrition and body composition of elite rhythmic gymnasts from Bulgaria. International Journal of Sports Science \& Coaching. 2020;15(1):108-16. https://doi.org/10.1177/1747954119892803

49.Kolimechkov S, Yanev I, Kiuchukov I, Petrov L, Alexandrova A, Zaykova D, et al. Nutritional status and body composition of young artistic gymnasts from Bulgaria. Journal of Applied Sports Sciences. 2019;1:39-52. https://doi.org/10.37393/jass.2019.01.4

50.US Department of Agriculture. Agricultural Research Service, Nutrient Data Laboratory. USDA National Nutrient Database for Standard Reference, Release 28. Version Current: September 2015, slightly revised May 2016; 2015.

51.STK-SPORT. Food Frequency Questionnaire [Internet]. 2020 [updated 2020 Jun 15; cited 2020 Nov 30]. Available from: https://www.stk-sport.co.uk/food-frequencyquestionnaire.html

52.Harris J, Benedict F. A Biometric Study of Basal Metabolism in Man. Washington DC: Carnegie Institute of Washington; 1919. P. 1-266.

53.Grove JR, Main LC, Partridge K, Bishop DJ, Russell S, Shepherdson A, et al. Training distress and performance readiness: laboratory and field validation of a brief self-report measure. Scandinavian Journal of Medicine \& Science in Sports. 2014;24(6):e483- 90. https://doi.org/10.1111/sms.12214

54.Boudreau C. Nutrition: Fueling for Performance. Riewald S, Rodeo S, editors. Science of Swimming Faster. Human Kinetics; 2015. https://doi.org/10.5040/9781492595854 


\section{Information about the authors:}

Lubomir Petrov; https://orcid.org/0000-0003-1209-959X; dr.lubomir.petrov@gmail.com; National Sports Academy; Sofia, Bulgaria.

Albena Alexandrova; https://orcid.org/0000-0002-7007-3665; a_alexandrova_bas@yahoo.com; National Sports Academy; Sofia, Bulgaria.

Mihail Kachaunov; https://orcid.org/0000-0002-6877-6054; mihail.kachaunov@gmail.com; National Sports Academy; Sofia, Bulgaria.

Radoslav Penov; https://orcid.org/0000-0002-3355-0725; fighters.nsa@abv.bg; National Sports Academy; Sofia, Bulgaria.

Tanya Sheytanova; https://orcid.org/0000-0003-0906-6834; tanyasheytanova@mail.bg; National Sports Academy; Sofia, Bulgaria.

Stefan Kolimechkov; (Corresponding author); https://orcid.org/0000-0003-0112-2387; dr.stefan.kolimechkov@gmail.com; STK SPORT; London, United Kingdom.

Cite this article as:

Petrov L, Alexandrova A, Kachaunov M, Penov R, Sheytanova T, Kolimechkov S. Effect of glutathione supplementation on swimmers' performance. Pedagogy of Physical Culture and Sports, 2021;25(4):215-224.

https://doi.org/10.15561/26649837.2021.0403

This is an Open Access article distributed under the terms of the Creative Commons Attribution License, which permits unrestricted use, distribution, and reproduction in any medium, provided the original work is properly cited (http://creativecommons.org/licenses/by/4.0/deed.en).

Received: 23.03.2021

Accepted: 12.04.2021; Published: 30.08.2021 